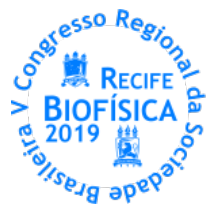

\title{
EFEITO DE REGULAÇÃO DE CARGAS NOS POTENCIAIS DE INTERAÇÃO DE PROTEINAS MODELO
}

\author{
Fredderico Camilo Machado ${ }^{1 *}$, Francesco Spinozzi ${ }^{2}$, Leandro R. S. Barbosa ${ }^{1}$ \\ ${ }^{1}$ Instituto de FÍsica, Universidade de São Paulo, São Paulo, Brasil \\ ${ }^{1}$ Department of Life and Environmental Sciences - DiSVA, Universita` Politecnica delle Marche, Ancona, Italy \\ *fredderico.machado@usp.br
}

\section{RESUMO}

A Regulação de cargas de proteĺnas é um assunto que está sendo muito estudado por vários grupos de pesquisas ao redor do mundo. A principal ideia desta metodologia desenvolvida nos anos 50 é considerar uma eventual flutuação no valor das cargas na superfície proteica, gerando uma distribuic, ão de cargas não constante neste ensemble. Esta distribuição pode ser afetada pela presença de uma outras macromoléculas, como proteínas e polímeros, ou mesmo devido à mudanças no meio, como adição de sais na solução ou variação de pH. Em vários estudos, como por exemplo análise do potencial de interação de proteínas a partir de dados de espalhamento de raio-X a baixos ângulos (SAXS, do inglês Small Angle $X$-ray Scattering), as cargas superficiais das proteĺnas são consideradas constantes a um pH fixo. 0 intuito desse projeto de pesquisa é observar os efeitos de regulação de cargas a partir dos potenciais de interação proteína-proteína, utilizando a técnica de SAXS. A partir dos dados de SAXS é possível obter informações estruturais sobre a proteína, como: massa molecular, raio de giro, fator de forma, $P$ (q) e também informações de como a proteĺna interage com outras em solução, dada pela função de interferência, S(q). A função de interferência está relacionado com a transformada de Fourier da função de correlac, ão total $h(r),(=g(r)-1)$, sendo $g(r)$ a função de distribuição radial, que dá a probabilidade de encontrar uma partícula a uma distância $r$, de uma partícula de referência. Vale salientar que a função $h(r)$ pode ser obtida através da resolução da equação de Orstein-Zernike. Neste projeto de pesquisa escolhemos a relaçao de fechamento RPA (do inglês, Random Phase Approximation). Nesta relação de fechamento, o potencial total de interação entre as proteínas é dividido em duas contribuições: Potencial de referência, dado pelo potencial de esfera dura; Potencial de perturbação, dado pelos potenciais Coulombiano, Potencial de Kirkwood (vindo da teoria de regulação de cargas) e potencial atrativo tipo Yukawa. Foram feitos simulações para Albumina de Soro Bovina e Lisozima e comparados com medidas experimentais. Para a primeira, o termo de regulação de carga não influenciou de maneira significativa o potencial atrativo (tipo Yukawa). Para pH's 4 e 5 , por exemplo, apesar da inclusão do termo de variância da carga, o valor do potencial no contato, $J(k B T)$, não teve seu valor alterado. Já para a Lisozima, nos $\mathrm{pH}$ 's perto do ponto isoelétrico ( $\mathrm{pl})$, o potencial no contato teve seu valor diminuido, mostrando assim que a regulação de cargas é um fator importante para essa proteína. Devido a esses resultados, será testado a hipotese da regulação de cargas ser mais evidente para proteínas de menor tamanho. Para isso, será utilizado a proteĺna Citocromo C de coração de boi. 